Mazur Karol, Machaj Dominik, Jastrzębska Sandra, Placzek Alicja, Mazur Dominika. Prevention and treatment of high altitude cerebral edema (HACE). Journal of Education, Health and Sport. 2020;10(2):120-125. eISSN 2391-8306. DOI http://dx.doi.org/10.12775/JEHS.2020.10.02.016

https://apcz.umk.pl/czasopisma/index.php/JEHS/article/view/JEHS.2020.10.02.016

https://zenodo.org/record/3678378

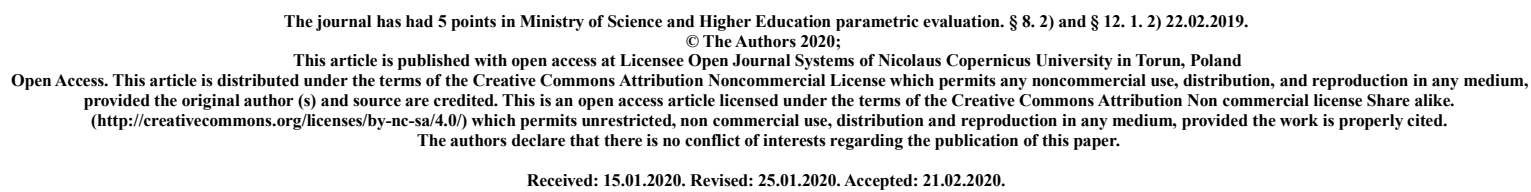

\title{
Prevention and treatment of high altitude cerebral edema (HACE)
}

\section{Karol Mazur, Dominik Machaj, Sandra Jastrzębska, Alicja Placzek, Dominika Mazur}

Karol Mazur, mazurkaro179@gmail.com, Faculty of Medicine, Medical University of Lublin, Chodźki Street 19, 20-093 Lublin, Poland

Dominik Machaj, dominik5a4@tlen.pl, Faculty of Medicine, Medical University of Lublin, Chodźki Street 19, 20-093 Lublin, Poland

Sandra Jastrzębska, sandra0189@gmail.com, Faculty of Medicine, Medical University of Lublin, Chodźki Street 19, 20-093 Lublin, Poland

Alicja Płaczek, alicja60@poczta.onet.pl, Medical Faculty, University of Rzeszow, Pigonia Street 6, 35-310 Rzeszow, Poland

Dominika Mazur, dominika.hul20@gmail.com, Medical Faculty, University of Rzeszow, Pigonia Street 6, 35-310 Rzeszow, Poland

\section{Summary:}

High altitude cerebral edema (HACE) is often a severe and potentially fatal manifestation of acute mountain sickness (AMS). It usually develops within the first 2 in individuals rapidly ascending at altitudes above $4000 \mathrm{~m}$. The main cause of HACE is hypoxia, because of reduced oxygen level at high altitude.

The aim of this study was to assess the methods of prevention and treatment of high altitude cerebral edema (HACE). Our study material consisted of publications, which were found in PubMed, ResearchGate and Google Scholar databases. The first step was to find proper publications from the last 30 years. The second step was to carry out an overview of the found publications.

Methods of prevention of acute mountain sickness are highly effective in high altitude cerebral edema prevention. Many studies established the role of gradual ascent and staged ascent as well as administration of acetazolamide and dexamethasone in AMS prevention, and therefore in HACE prevention. Methods of treatments of acute mountain sickness are highly effective in high altitude cerebral edema treatment. Several researches proved the role of descent, administration of acetazolamide and dexamethasone, oxygen therapy as well as use of portable hyperbaric chamber in AMS treatment, and therefore in HACE treatment. However HACE treatment requires greater descent and larger doses of dexamethasone. Also duration of recovery is longer.

Key words: high altitude cerebral edema, HACE, prevention, treatment 


\section{INTRODUCTION AND PURPOSE}

High altitude cerebral edema (HACE) is often a severe and potentially fatal manifestation of acute mountain sickness (AMS). HACE has relatively lower incidence rate than AMS and is normally preceded by symptoms of AMS. It usually develops within the first 2 in individuals rapidly ascending at altitudes above $4000 \mathrm{~m}$ [1]. The neurological features of HACE are characterized by neurological disorders of varying degree: disturbance of consciousness, ataxia, papilledema, urinary retention or incontinence, abnormal plantar reflexes, pupil difference, visual field loss, speech difficulty and hearing loss [2]. Early recognition of symptoms of HACE is essential, because this condition may rapidly progress to death [1].

The main cause of HACE is hypoxia, because of reduced oxygen level at high altitude. Hypoxia leads to cerebral vasodilatation, that effects increased both cerebral blood flow and cerebral blood volume. This process causes cerebral capillary hypertension, that results in increased capillary permeability and therefore capillary leakage. Hypoxia also induces synthesis of vascular endothelial growth factor, bradykinin, histamine, arachidonic acid, oxygen free radicals and nitric oxide. These biochemical factors lead to altered permeability of the blood-brain barrier, that effects fluid penetration. This processes result in increased intracranial pressure and therefore cerebral edema [2].

The aim of this study was to assess the methods of prevention and treatment of high altitude cerebral edema (HACE). Our study material consisted of publications, which were found in PubMed, ResearchGate and Google Scholar databases. In order to find the proper publications, the search has been conducted with the use of a combination of key words like: "high altitude cerebral edema", "HACE", "prevention", "treatment". The first step was to find proper publications from the last 30 years .The second step was to carry out an overview of the found publications.

\section{DESCRIPTION OF THE STATE OF KNOWLEDGE}

\section{Prevention}

None of the studies have prospectively examined the efficacy of methods of prevention of high altitude cerebral edema, and therefore further research is needed. However many researches that have assessed prospectively different methods of prevention of acute mountain sickness, revealed their effectiveness in HACE prevention. Therefore it is reasonable to use them due to similar pathophysiology of AMS and HACE [2,3]. Bloch et al., 
Beidleman et al. and Baggish et al. proved that gradual ascent and staged ascent are highly effective in preventing of acute mountain sickness [4,5,6]. Forwand et al., van Patot et al., Gertsch et al., Basnyat et al. (2011) and Basnyat et al. (2011) in their researches established a role of acetazolamide in prevention of acute mountain sickness [7,8,9,10,11). Johnson et al., Ellsworth et al. (1987), Ellsworth et al. (1991) and Maggiorini et al. proved the effectiveness of administration of dexamethasone in AMS prevention [12,13,14,15].

Gradual ascent and staged ascent remain the most effective methods of prevention of high altitude cerebral edema. Individuals travelling above $3000 \mathrm{~m}$ should not increase their sleeping elevation by more than $500 \mathrm{~m} /$ day and should include a rest day (ie, no ascent to higher sleeping elevation) every 3 to 4 days. The recommended adult dose of acetazolamide for HACE prevention is $125 \mathrm{mg}$ every $12 \mathrm{~h}$. The pediatric dose is $2.5 \mathrm{mg} / \mathrm{kg} / \mathrm{dose}$ (maximum $125 \mathrm{mg} /$ dose) every $12 \mathrm{~h}$. The recommended adult dose of dexamethasone for HACE prevention are $2 \mathrm{mg}$ every $6 \mathrm{~h}$ or $4 \mathrm{mg}$ every $12 \mathrm{~h}$. Very high doses ( $4 \mathrm{mg}$ every $6 \mathrm{~h}$ ) may be considered in very high-risk situations, such as military or search and rescue personnel being airlifted to altitudes $>3500 \mathrm{~m}$ with immediate performance of physical activity, but should not be used except in these limited circumstances Dexamethasone should not be used for prophylaxis in pediatric patients [3].

\section{Treatment}

None of the studies have prospectively examined the efficacy of methods of treatment of high altitude cerebral edema, and therefore further research is needed. However many researches that have assessed prospectively different methods of treatment of acute mountain sickness, revealed their effectiveness in HACE treatment. Therefore it is reasonable to use them due to similar pathophysiology of AMS and HACE [2,3]. Bärtsch et al., Hackett et al. (2001), Hackett et al. (2004) and Imray et al. proved that descent is the primary method of AMS treatment [1,2,16,17]. Ferazzini et al., Hackett et al. (1988), Hackett et al. (2004), Levine et al., Wright et al. and Keller et al. established the role of dexamethasone in AMS treatment $[2,18,19,20,21,22]$. Pollard et al. reported the use of dexamethasone in treatment AMS in pediatric patients [23]. Grissom et al. showed the role of acetazolamide in AMS treatment [24]. Freeman et al., Austin and Zafren reported the use of portable hyperbaric chambers in the treatment of high altitude cerebral edema [25,26,27].

Before initiating treatment of high altitude cerebral edema, consideration should be given to other causes of symptoms resemble to HACE [3]. Differential diagnosis shall include: carbon monoxide poisoning, dehydration, exhaustion, hypoglycemia, hypothermia, and 
hyponatremia [2]. If HACE is suspected or diagnosed, dexamethasone with acetazolamide shoud be administered, oxygen therapy should be started and descent to lower elevation should be initiated. Individuals should try to descend at least $1000 \mathrm{~m}$ or until symptoms resolve. The recommended adult dose of acetazolamide for HACE treatment is $250 \mathrm{mg}$ every $12 \mathrm{~h}$. The pediatric dose is $2.5 \mathrm{mg} / \mathrm{kg}$ /dose (maximum $125 \mathrm{mg} /$ dose) every $12 \mathrm{~h}$. The recommended adult dose of dexamethasone for HACE treatment is $8 \mathrm{mg}$ once, then $4 \mathrm{mg}$ every $6 \mathrm{~h}$. The pediatric dose is $0,15 \mathrm{mg} / \mathrm{kg} /$ dose (maximum $4 \mathrm{mg} /$ dose) every $6 \mathrm{~h}$. Oxygen should be delivered by nasal cannula or mask at flow rates sufficient to achieve an $\mathrm{SpO} 2$ $>90 \%$. If descent is infeasible or delayed, oxygen therapy should be continued or the individual should be placed in a portable hyperbaric chamber [3].

\section{CONCLUSIONS}

1. Methods of prevention of acute mountain sickness are highly effective in high altitude cerebral edema prevention.

2. Many studies established the role of gradual ascent and staged ascent as well as administration of acetazolamide and dexamethasone in AMS prevention, and therefore in HACE prevention.

3. Methods of treatments of acute mountain sickness are highly effective in high altitude cerebral edema treatment.

4. Several researches proved the role of descent, administration of acetazolamide and dexamethasone, oxygen therapy as well as use of portable hyperbaric chamber in AMS treatment, and therefore in HACE treatment.

5. However HACE treatment requires greater descent and larger doses of dexamethasone. Also duration of recovery is longer. 


\section{LIST OF REFERENCES:}

1. Hackett PH, Roach RC. High-altitude illness. N. Engl. J. Med. 2001; 345: 107-14.

2. Hackett P.H., Roach R.C. High altitude cerebral edema. High Altitude Medicine \& Biology 2004;5(2):136-46.

3. Luks A.M., Auerbach P.S., Freer L., Grissom C.K., Keyes L.E., Intosh M.C. et al. Wilderness Medical Society Practice Guidelines for the prevention and treatment of acute altitude illness: 2019 update. Wilderness Environ Med. 2019; 30: S3-S18.

4. Bloch, K.E., Turk, A.J.,,3 Maggiorini, M., Hess, T., Merz, T., Bosch, M.M. et al. Effect of ascent protocol on acute mountain sickness and success at Muztagh Ata, 7546 m. High Alt Med Biol. 2009; 10: 25-32

5. Beidleman, B.A., Fulco, C.S., Muza, S.R., Rock, P.B., Staab, J.E., Forte, V.A. et al. Effect of six days of staging on physiologic adjustments and acute mountain sickness during ascent to 4300 meters. High Alt Med Biol. 2009; 10: 253-260

6. Baggish, A.L., Fulco, C.S., Muza, S., Rock, P.B., Beidleman, B., Cymerman, A. et al. The impact of moderate-altitude staging on pulmonary arterial hemodynamics after ascent to high altitude. High Alt Med Biol. 2010; 11: 139-145

7. Forwand, S.A., Landowne, M., Follansbee, J.N., and Hansen, J.E. Effect of acetazolamide on acute mountain sickness. N Engl J Med. 1968; 279: 839-845

8. van Patot, M.C., Leadbetter, G. 3rd, Keyes, L.E., Maakestad, K.M., Olson, S., and Hackett, P.H. Prophylactic low-dose acetazolamide reduces the incidence and severity of acute mountain sickness. High Alt Med Biol. 2008; 9: 289-293

9. Gertsch, J.H., Basnyat, B., Johnson, E.W., Onopa, J., and Holck, P.S. Randomised, double blind, placebo controlled comparison of Ginkgo biloba and acetazolamide for prevention of acute mountain sickness among Himalayan trekkers: the prevention of high altitude illness trial (PHAIT). BMJ. 2004; 328: 797

10. Basnyat B Gertsch JH Johnson EW, et al. Efficacy of low-dose acetazolamide (125 mg BID) for the prophylaxis of acute mountain sickness: a prospective, double-blind, randomized, placebo-controlled trial. High Alt Med Biol 2003; 4:45-52.

11. Basnyat, B., Holck, P.S., Pun, M., Halverson, S., Szawarski, P., Gertsch, J. et al. Spironolactone does not prevent acute mountain sickness: a prospective, double-blind, randomized, placebocontrolled trial by SPACE Trial Group (spironolactone and acetazolamide trial in the prevention of acute mountain sickness group). Wilderness Environ Med. 2011; 30: 3-18.

12. Johnson T.S., Rock P.B., Fulco C.S. Prevention of acute mountain sickness by dexamethasone. N Engl J Med 1984; 310: 683-686.

13. Ellsworth, A.J., Larson, E.B., and Strickland, D. A randomized trial of dexamethasone and acetazolamide for acute mountain sickness prophylaxis. Am J Med. 1987; 83: 1024-1030 
14. Ellsworth, A.J., Meyer, E.F., and Larson, E.B. Acetazolamide or dexamethasone use versus placebo to prevent acute mountain sickness on Mount Rainier. West J Med. 1991; 154: 289-293.

15. Maggiorini M., Brunner-La Rocca, H.P., Peth, S., Fischler, M., Bohm, T., Bernheim, A. et al. Both tadalafil and dexamethasone may reduce the incidence of high-altitude pulmonary edema: a randomized trial. Ann Intern Med. 2006; 145: 497-506

16. Bärtsch P., Swenson E.R., Acute High-Altitude Illnesses. N Engl J Med 2013; 368:2294-2302.

17. Imray C, Wright A, Subudhi A, Roach R. Acute mountain sickness: pathophysiology, prevention, and treatment. Prog. Cardiovasc. Dis. 2010; 52: 467-84.

18. Ferrazzini G., Maggiorini M., Kriemler, S., Bartsch, P., and Oelz, O. Successful treatment of acute mountain sickness with dexamethasone. Br Med J (Clin Res Ed). 1987; 294: 1380-1382

19. Hackett P.H., Roach, R.C., Wood, R.A., Foutch, R.G., Meehan, R.T., Rennie, D. et al. Dexamethasone for prevention and treatment of acute mountain sickness. Aviat Space Environ Med. 1988; 59: 950-954

20. Levine, B.D., Yoshimura, K., Kobayashi, T., Fukushima, M., Shibamoto, T., and Ueda, G. Dexamethasone in the treatment of acute mountain sickness. N Engl J Med. 1989; 321: 17071713

21. Wright A, Brearey S, Imray C. High hopes at high altitudes: pharmacotherapy for acute mountain sickness and high-altitude cerebral and pulmonary oedema. Expert Opinion on Pharmacotherapy 2008;9(1):119-27.

22. Keller H.R. et al. Simulated descent $\mathrm{v}$ dexamethasone in treatment of acute mountain sickness: a randomised trial. Br Med J 1995; 310(6989): 1232-1235.

23. Pollard, A.J., Niermeyer, S., Barry, P., Bartsch, P., Berghold, F., Bishop, R.A. et al. Children at high altitude: an international consensus statement by an ad hoc committee of the International Society for Mountain Medicine, March 12, 2001. High Alt Med Biol. 2001; 2: 389-403

24. Grissom, C.K., Roach, R.C., Sarnquist, F.H., and Hackett, P.H. Acetazolamide in the treatment of acute mountain sickness: clinical efficacy and effect on gas exchange. Ann Intern Med. 1992; 116: $461-465$

25. Freeman K., Shalit M., and Stroh, G. Use of the Gamow bag by EMT-basic park rangers for treatment of high-altitude pulmonary edema and high-altitude cerebral edema. Wilderness Environ Med. 2004; 15: 198-201

26. Austin D. Gamow bag for acute mountain sick-ness. Lancet 1998; 351(9118):1815

27. Zafren K. Gamow bag for high-altitude cerebraloedema. Lancet 1998; 352(9124):325-326. 